\title{
Can Coronavirus Disease-19 Lead to Temporomandibular Joint Disease?
}

\author{
Dinesh Rokaya $^{1 *}$, Sittichai Koontongkaew ${ }^{2}$ \\ ${ }^{1}$ Department of Prosthodontics, International College of Dentistry Walailak University, Bangkok 10400, Thailand; ${ }^{2}$ Department \\ of Oral Bioscience, International College of Dentistry Walailak University, Bangkok 10400, Thailand
}

Abstract

Edited by: Mirko Spiroski

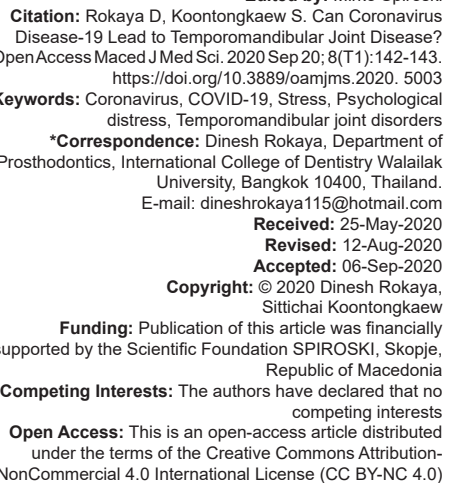

BACKGROUND: The coronavirus disease (COVID-19) has become pandemic spreading globally. The outbreak of COVID-19 has led to psychological problems and compromised the mental health of the people. Temporomandibular disorder (TMD) shows the pain and dysfunction of the masticatory apparatus. History of trauma, stress, psychosocial impairment, drinking alcohol, and catastrophizing are related to the TMD.

AIM: We aimed to present some background information, in which COVID-19 may be correlated with TMD.

METHODS: The outbreak of COVID-19 has led to psychological problems and compromised the mental health of the people.

RESULTS: The outbreak of COVID-19 has led to psychological problems and compromised the mental health of the people, not those only who suffered from coronavirus but also to those in self-isolation, social-distancing, and quarantined. TMD shows the pain and dysfunction of the masticatory apparatus, and one of the major causes of TMD is stress and psychosocial impairment apart from drinking alcohol and history of trauma. Hence, TMD may be correlated with COVID-19. The consequences of anxiety, depression, and stress in people from the outbreak of COVID-19 may lead to TMD.

CONCLUSION: Hence, COVID-19 may be correlated with TMD as one of the major causes of TMD is stress and psychosocial impairment.

The coronavirus disease (COVID-19) has become pandemic spreading globally over 210 countries [1], [2]. At present, many countries are locked down, and people are on self-quarantine to limit the spread of disease. COVID-19 is a respiratory virus showing symptoms such as fever, fatigue, dry cough, and dyspnea. Most infected people show mild-tomoderate respiratory illness and recover. Older people with underlying medical diseases such as diabetes, cardiovascular disease, chronic respiratory disease, and cancer have a higher chance of developing severe illness, causing mortality [2], [3]. The WHO has given details of COVID and mentions that there are no specific vaccines or other therapies developed for COVID-19 till now [2]. However, many ongoing clinical trials are evaluating potential treatments. Improvement in viral metagenomics could potentially aid the diagnosis of COVID-19 cases and the management of this pandemic [4].

The outbreak of COVID-19 has led to psychological problems and compromised the mental health of the people, not those only who suffered from coronavirus but also to those in self-isolation, socialdistancing, and quarantined [5], [6]. In addition, people suffer from fear, anxiety, stress, and self-efficacy [7], and this also led COVID-19-suicides [8]. Most vulnerable are those with existing mental health problems such as
Ioneliness, depression, and isolation. Enforced isolation and quarantine interrupted normal social live causing emotional imbalance, economic shutdown, financial and future insecurities, and psychological fear.

Temporomandibular disorder (TMD) shows the pain and dysfunction of the masticatory apparatus and the temporomandibular joint. History of trauma, stress, drinking alcohol, psychosocial impairment, and catastrophizing are related to the TMD [9], [10], [11], [12]. Anxiety, depression, and stress contribute to chronic upregulation of the hypothalamic-pituitary-adrenal axis, which lead to TMD [9]. Hence, TMD may be correlated with COVID-19. The consequences of anxiety, depression, and stress in people from the outbreak of COVID-19 may lead to TMD.

The provision of care and support in people is a high priority service [2]. Work from home, spending time indoors with our families, connect to friends on social media, and engage in mindfulness activities may help to reduce the stress. A multidisciplinary clinical approach, including dentistry, is needed in the diagnosis of TMD and the treatment for this condition through a clinical practice supported by scientific knowledge [13]. Psychological intervention and mental health support are needed to reduce anxiety and stress as a part of the TMD treatment. Psychological counseling is also required to reduce anxiety and stress in severe cases. 


\section{Authors' Contributions}

DR and SK conceptualized and designed the study. DR drafted the first manuscript. SK reviewed and edited the manuscript. All authors are responsible for the integrity of the data.

\section{References}

1. Chakraborty C, Sharma AR, Bhattacharya M, Sharma G, Lee SS. The 2019 novel coronavirus disease (COVID-19) pandemic: A zoonotic prospective. Asian Pac J Trop Med. 2020;13(6):242-6.

2. Coronavirus. Available from: https://www.who.int/emergencies/ diseases/novel-coronavirus-2019. [Lastaccessed on 2020 May 17].

3. LiuK, Chen Y, LinR, HanK. Clinical features of COVID-19inelderly patients: A comparison with young and middle-aged patients. $J$ Infect. 2020;80:e14-8. https://doi.org/10.1016/j.jinf.2020.03.005 PMid:32171866

4. Borroni D, Gadhvi K. The need of non-traditional techniques to screen for the virus. Open Access Maced J Med Sci. 2020;8(T1):1-2. https://doi.org/10.3889/oamjms.2020.4773

5. Jiang $\mathrm{X}$, Deng $\mathrm{L}$, Zhu $\mathrm{Y}$, Ji $\mathrm{H}$, Tao L, Liu L, et al. Psychological crisis intervention during the outbreak period of new coronavirus pneumonia from experience in Shanghai. Psychiatry Res. 2020;286:112903. https://doi.org/10.1016/j. psychres.2020.112903

PMid:32146245

6. Mukhtar S. Mental health and psychosocial aspects of coronavirus outbreak in Pakistan: Psychological intervention for public mental health crisis. Asian J Psychiatr. 2020;51:102069. https://doi.org/10.1016/j.ajp.2020.102069

\section{PMid:32344331}

7. Xiao H, Zhang Y, Kong D, Li S, Yang N. The effects of socia support on sleep quality of medical staff treating patients with coronavirus disease 2019 (COVID-19) in January and February 2020 in China. Med Sci Monit. 2020;26:e923549. https://doi. org/10.12659/msm.923921

\section{PMid:32132521}

8. Thakur V, Jain A. COVID 2019-suicides: A global psychologica pandemic. Brain Behav Immun. 2020;88:952-3. https://doi. org/10.1016/j.bbi.2020.04.062

PMid:32335196

9. Staniszewski K, Lygre H, Bifulco E, Kvinnsland S, Willassen L, Helgeland $\mathrm{E}$, et al. Temporomandibular disorders related to stress and HPA-axis regulation. Pain Res Manag. 2018;2018:7020751. https://doi.org/10.1155/2018/7020751

10. Rokaya D, Suttagul K, Joshi S, Bhattarai BP, Shah PK, Dixit S. An epidemiological study on the prevalence of temporomandibular disorder and associated history and problems in Nepalese subjects. J Dent Anesth Pain Med. 2018;18(1):27-33. https:// doi.org/10.17245/jdapm.2018.18.1.27

PMid:29556556

11. Manfredini D, Landi N, Bandettini Di Poggio A, Dell'Osso L, Bosco M. A critical review on the importance of psychological factors in temporomandibular disorders. Minerva Stomatol. 2003;52(6):321-6.

PMid: 12874536

12. Augusto VG, Perina KC, Penha DS, Dos Santos DC, Oliveira VA. Temporomandibular dysfunction, stress and common mental disorderin university students.Acta Ortop Bras. 2016;24(6):330-3. https://doi.org/10.1590/1413-785220162406162873 PMid:28924361

13. Gameiro GH, Da Silva Andrade A, Nouer DF, Ferraz De Arruda Veiga MC. How may stressful experiences contribute to the development of temporomandibular disorders? Clin Oral Investig. 2006;10(4):261-8. https://doi.org/10.1007/ s00784-006-0064-1

PMid:16924558 